\title{
Currículo e Formação de Professores: uma visão integrada da construção do conhecimento profissional
}

\author{
Teacher Training and Curriculum: an integrated view of \\ professional knowledge construction
}

Currículum y Formación Docente: una visión integrada de la construcción del conocimiento profesional

Helena Maria dos Santos Felício ${ }^{[a]}$, Carlos Manuel Ribeiro da Silva $a^{[b]^{*}}$

[a] Universidade Federal de Alfenas, Alfenas, MG, Brasil

[b] Universidade do Minho, Braga, Portugal I

\section{Resumo}

Este trabalho tem por objetivo analisar os aspectos da perspectiva integrada de currículo na formação inicial de professores do Brasil. Fundamentados no modelo de "currículo formativo integrado", realizamos a análise documental dos Projetos Pedagógicos dos Cursos de Pedagogia de Universidade Federais Brasileiras para compreender quais e como os componentes do modelo integrado de formação estão presentes nesses documentos. Os

HMSF: Doutora em Educação, e-mail: helena.felicio@unifal-mg.edu.br CMRS: Doutor em Educação, e-mail: carlos@ie.uminho.pt 
resultados evidenciam: Em relação ao referencial de formação, os projetos apresentam justificativas que fundamentam a integração curricular na valorização dos processos de construção de conhecimento significativo. No que diz respeito à centralidade da prática, verificamos projetos que a concebem como eixo estruturante do curso e outros que a concentram em atividades de estágio. Quanto à organização das unidades curriculares, os projetos indicam organizações por eixos/núcleos temáticos, no entanto prevalece a justaposição das disciplinas. No que concerne à articulação com o contexto profissional, os cursos intencionam a alternância dos espaços formativos desde o início da formação. Finalmente, no que diz respeito ao desenvolvimento da práxis, constatamos a preocupação de formar o educador capaz de pensar a sua prática enquanto intervenção crítica no processo de ensino e de aprendizagem. Neste sentido, afirmamos que experiências pontuais não são suficientes para abarcar a complexidade da formação e da atuação profissional, sendo necessário reconhecer o caráter transformador de um currículo integrado, como possibilidade formativa de um perfil profissional que responda às exigências do contexto educacional contemporâneo.

Palavras-chave: Formação de Professores. Currículo Formativo Integrado. Curso de Pedagogia.

\section{Abstract}

This work has as a point to analyze the aspects of integrated perspective of curriculum in the basic training of Brazilian teachers. We based the model of "Integrated Curriculum Training", we have performed a file analysis in pedagogical projects of the pedagogy majors from Brazilian Federal Universities to understand which and how the elements of training integrated model are present on these files. The results showed: About Training referential, the projects show justifications that base in the valuation of significant knowledge construction processes. What about the centrality of practice, we see projects that either conceive it as a course structural axis or condense it all in internship activities. About the curricular unit organizations, the projects evince organizations by theme centers/axes. However the juxtaposition of disciplines prevails. What concerns to the professional context linkage, the majors intend to an exchanging training spaces since the training beginning. Finally, what about the development of praxis, we verify the concern of training the educator able to think of its own practice as while a critic intervention in the teaching and learning process. In this sense, we assure punctual experiences are not 
enough to involve the training complexity and the professional performance, it is necessary recognize the transformer feature of a integrated curriculum, as a training possibility of a professional profile that fulfill the contemporary educational context.

Keywords: Teacher Training. Integrated Curriculum Training. Pedagogy Major.

\section{Resumen}

Este trabajo tiene como objetivo analizar los aspectos de la perspectiva integrada de en la formación inicial en Brasil. Basados en el modelo de "currículum formativo integrado", realizamos un análisis documental de los Proyectos Pedagógicos de los cursos de Pedagogía de Universidades Federales Brasileñas para comprender cuáles y cómo los componentes del modelo integrado de formación están presentes en estos documentos. Los resultados evidencian: En cuanto al referencial de formación, los proyectos presentan justificativas que fundamentan la integración curricular en la valoración de los procesos de construcción de conocimiento significativo. Con respecto a la centralidad de la práctica, encontramos proyectos que la conciben como eje estructural del curso y otros que la concentran en actividades de pasantía. Cuanto a la organización de las unidades curriculares, los proyectos indican organizaciones por ejes/núcleos temáticos, sin embargo prevalece la yuxtaposición de disciplinas. Con respecto a la articulación con el contexto profesional, los cursos intencionan la alternancia de los espacios desde el inicio de la formación. Finalmente, en relación al desarrollo de la praxis, constatamos la preocupación de formar el educador capaz de pensar su práctica como una intervención crítica en el proceso de enseñanza y aprendizaje. En este sentido, afirmamos que experiencias específicas no son suficientes para cubrir la complejidad de la formación y la actuación profesional, siendo necesario reconocer el carácter transformador de un currículum integrado, como posibilidad formativa de un perfil profesional que responda con los requisitos del contexto educativo contemporáneo.

Palabras clave: Formación de Profesores. Currículum Formativo Integrado. Curso de Pedagogía. 


\section{Introdução}

É com veemência, que a integração curricular tem sido considerada nos atuais discursos os quais orientam as políticas e as práticas curriculares da Educação Básica do Brasil. Esta tônica é apresentada pelas Diretrizes Curriculares Nacionais para a Educação Básica (BRASIL, 2010), quando enfatiza que o trabalho docente dos professores que atuam na Educação Infantil e nos anos iniciais do Ensino Fundamental deve ser pautado na perspectiva de integrar as diferentes áreas do conhecimento, superando a fragmentação do mesmo e a compartimentação disciplinar que predominou, por muito tempo, como característica do trabalho pedagógico.

Para que esta premissa seja efetiva no cotidiano escolar, precisamos considerar como a formação inicial de professores tem considerado a integração curricular em suas propostas, a fim de que a atuação profissional deste futuro professor se desenvolva segundo esta perspectiva. Assim, defendemos que um olhar aprofundado para cursos de formação inicial de professores e seus currículos, torna-se essencial a fim de perceber como tais cursos têm incorporado abordagens e experiências formativas consideradas integradoras para a construção do conhecimento profissional pertinente e para o seu desenvolvimento enquanto práticos reflexivos e críticos.

Neste sentido, este trabalho tem por objetivo analisar como a dimensão integradora está presente nos currículos de formação inicial de professores para a Educação Infantil e 1. Ciclo do Ensino Fundamental no Brasil.

\section{Formação de professores em uma perspectiva integrada de currículo}

As exigências da sociedade, cada vez mais complexas, constituídas sobre o acesso, domínio e produção do conhecimento, questionam a escola quanto às suas funções e as desafiam no sentido de se transformarem constantemente, a fim de que o seu papel social seja cumprido. Consequentemente, essas exigências demandam professores cada vez 
mais competentes, adaptados e capazes profissionalmente, para responderem a tais exigências.

Este cenário instiga a área da formação inicial de professores sobre a qualidade dos processos formativos desenvolvidos pelas instituições formadoras. Tais processos devem ir ao encontro do perfil de professor que vem sendo exigido nos contextos atuais, o qual assuma a profissão como um serviço social e humano; construa, permanentemente, conhecimentos e habilidades para desempenhar suas funções de fazer o outro aprender; que seja capaz de estabelecer relações pessoais e profissionais com os educandos; e, que seja comprometido e responsável com o desenvolvimento de um trabalho coletivo com seus pares (MUÑOZ, 2006, p. 34-42).

Desta forma, o currículo e a sua organização assumem-se como elementos de destaque, uma vez que eles revelam opções acerca de um determinado modelo de formação profissional, caracterizado pelas articulações que se estabelecem, no seu interior, entre os saberes teóricos e os saberes práticos, necessários à atividade docente e ao desenvolvimento profissional, cuja construção deve ser o objetivo de qualquer programa de formação.

No caso específico do currículo de formação inicial de professores, apesar de encontrarmos avanços, evidenciamos que a própria estrutura curricular se organiza a partir de uma especialização disciplinar, norteada pelas especificidades dos professores formadores, promovendo, assim, uma concepção de currículo como justaposição de disciplinas (FORMOSINHO, 2009), gerando obstáculos no processo de formação inicial de professores, como os indicados por Alonso e Silva:

(a) a preponderância do modelo transmissivo; (b) a concepção abstracta da teoria e da prática; (c) a descontextualização da formação; (d) a prevalência do individualismo; (e) a consideração dos professores como objecto de formação; (f) a estrutura celular e academicista das instituições de formação; ( $\mathrm{g}$ ) a separação entre as instituições de formação e as escolas; e (h) a falta de continuidade e interação entre as diferentes etapas da formação (ALONSO e SILVA, 2005, p. 47). 
Tais obstáculos são identificados no processo formativo, sobretudo porque, neste contexto de século XXI, o trabalho dos professores se desenvolve em uma realidade escolar em que é cada vez mais questionado pelas mudanças sociais, culturais, tecnológicas e econômicas, as quais demandam professores com capacidades e competências que extrapolem o ato de "transmitir" conteúdos.

O perfil profissional desejado para um professor dos tempos atuais supõe a capacidade de "diagnosticar problemas, de reflectir e investigar sobre eles, construindo uma teoria adequada (teorias práticas) que orientem a tomada de decisões" (ALONSO, 2007, p. 46), que esteja aberto às inovações e às constantes aprendizagens, que aceite a diversidade, que construa a partilha e o diálogo com seus pares, alunos e com os diversos agentes educativos, que promova a construção de um conhecimento holístico.

É possível perceber que os esforços empreendidos para a superação dos obstáculos mencionados para a formação de um profissional com o perfil descrito, ao mesmo tempo em que se constituem em desafio, abrem horizontes para a construção de propostas curriculares formativas fundamentadas em outras lógicas, para além da especialização disciplinar, como explicitada anteriormente. A perspectiva do currículo integrado na formação de professores se constitui como um desses horizontes.

Torna-se mais comum encontrarmos produções acerca do currículo integrado destinadas aos níveis da Educação Básica (BEANE, 2002; LOPES, 2008). No entanto, conceber a integração curricular na formação de professores, está para além de fazer uma simples transposição dos seus pressupostos de um nível (Educação Básica) para outro (Ensino Superior). Supõe construir uma outra lógica para o processo de formação, o que requer transformar por dentro, suas concepções e práticas, tanto individuais como coletivas.

$\mathrm{Na}$ certeza de que um currículo pautado pela justaposição não favorece esta formação desejada, acreditamos que integrar o currículo na formação inicial de professores pode oferecer contribuições mais significativas em tal processo. 
Aceitando a dificuldade de construir uma (re)orientação curricular na perspectiva integrada no Ensino Superior, sobretudo pela rigidez de suas estruturas organizativas e pela especialização, cada vez mais acentuada dos professores formadores, é preciso sustentar a convicção da necessidade de um processo formativo integrado para os futuros professores, que pode ser expressado a partir do seguinte esquema:

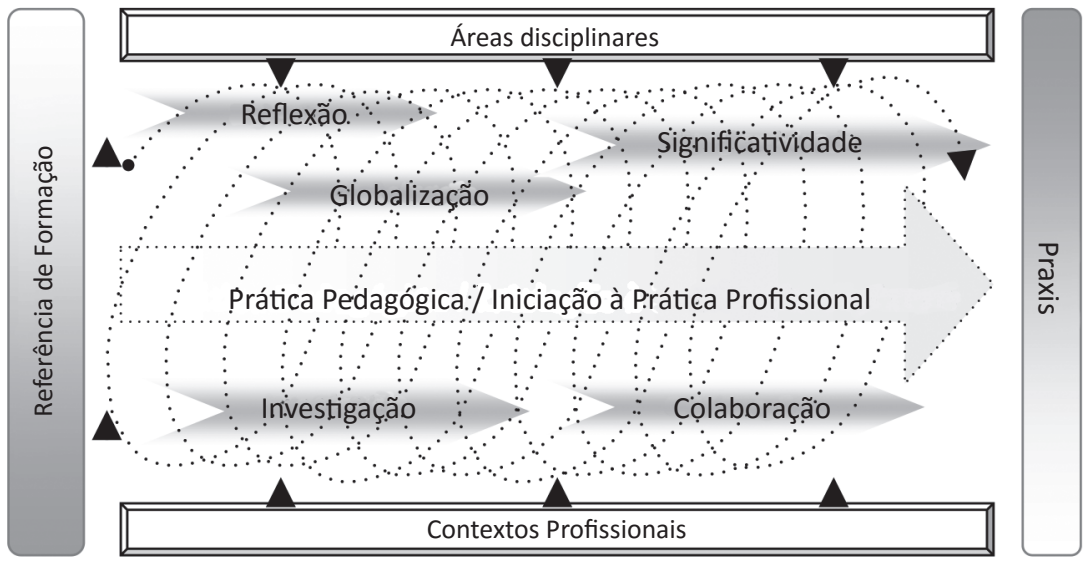

Figura 1 - Modelo Integrado de Formação (ALONSO; SILVA, 2005, p. 60)

Neste esquema evidenciamos o referencial de formação como ponto de partida para a construção deste modelo integrado de formação. Sua definição deve ser pautada em um enquadramento teórico, o qual sustente uma compreensão alargada do currículo, que justifique as intenções e ações no processo formativo, que estimule o entendimento deste currículo como "projeto de formação global e integrado, participado e partilhado por todos os intervenientes e contextos de formação" (SILVA, 2011, p. 700).

A iniciação à prática pedagógica assume a centralidade nesta proposta curricular, uma vez que o exercício profissional é a finalidade última de todo processo formativo, e para a qual devem estar convergidas todas as ações realizadas ao nível das áreas disciplinares, mediante a articulação vertical e horizontal dos conteúdos a serem trabalhados, onde 
não se espera que os formandos tornem-se especialistas numa ou noutra área, mas, que sejam capazes de articular e mobilizar os saberes das diferentes áreas disciplinares para responder aos desafios da realidade.

Assim, o enraizamento do currículo nos contextos de trabalho é um aspecto fundamental a ser considerado, pois o mesmo passa a ser estruturado levando em conta a articulação lateral com os contextos profissionais que "sustentem e deem sentido ao desenvolvimento pessoal e profissional dos alunos a formar, à luz do referencial de formação, permitindo processos de iniciação à prática profissional que informem uma determinada práxis a desenvolver pelos futuros professores" (SILVA, 2011, p. 709).

A práxis deste modelo formativo concebe-se como um movimento dialético de ação-reflexão-ação, alimentada por posturas metodológicas que privilegiam procedimentos investigativos, reflexivos e colaborativos, e ancorada no constante diálogo e partilha entre os sujeitos envolvidos, de modo que os mesmos, no decorrer do processo formativo, vão se constituindo como sujeitos transformados e transformadores da realidade objetiva e, neste caso, do contexto educacional no qual se inserem.

\section{A perspectiva integrada do currículo na formação inicial de professores}

Considerando os objetivos deste trabalho, elegemos os Projetos Pedagógicos dos cursos de Pedagogia, de 20 Universidades Federais Brasileiras, identificadas por letras (de A a E) e números, compreendendo todas as regiões do país, como corpus de análise, no intuito de compreender as concepções e as experiências integradoras que esses projetos intencionam materializar em seus currículos de formação.

Esta análise foi realizada a partir de uma abordagem qualitativa de pesquisa, em que a análise de conteúdo foi o procedimento metodológico utilizado neste processo investigativo, a partir de uma codificação temática em função dos componentes do Modelo Integrado de Formação, assumidos como categorias centrais neste estudo. 


\section{A concepção alargada do currículo enquanto referencial de formação}

Identificamos como concepção alargada do currículo as explicitações conceituais, que nos remetem a uma compreensão ampla, flexível e coerente, no que diz respeito à seleção e organização do conhecimento na formação de professores. Ao identificar projetos pedagógicos que concebem o currículo como "algo aberto e em movimento, que privilegia tanto o processo para definir diferentes percursos quanto os resultados a serem alcançados, [que deve ser visto] como uma rede" (A-1). Constatamos propostas que intencionam trabalhar na perspectiva de um currículo mais flexível, o que implica maior liberdade de ação para os professores, maior envolvimento, responsabilidade e formas diferenciadas de assumir o trabalho docente, sobretudo na necessidade de construção de redes colaborativas entre os profissionais.

Identificamos também a necessidade de assumir um currículo aberto à compreensão da realidade, como identificamos no seguinte excerto: "O currículo deverá, permanentemente, estar comprometido com a compreensão e explicitação da realidade educacional [...] em suas vinculações históricas com o contexto regional e nacional" (B-4).

Comprometer o currículo com a realidade educacional dos contextos envolventes, implica, por um lado, em estabelecer relações mais estreitas entre o espaço de formação e o espaço de atuação profissional, minimizando os efeitos negativos da academização da formação inicial de professores (FORMOSINHO, 2009) e valorizando o contexto educacional como espaço formativo de igual importância.

Por outro lado, supõe a construção de currículos mais equilibrados, que supere a hierarquização disciplinar clássica que, em muitos casos, está sedimentada nos currículos de formação inicial de professores, a fim de que outras dimensões, também necessárias, possam ser contempladas na formação deste professor. "O currículo expressa uma formação que busca superar a fragmentação e a hierarquização do trabalho pedagógico, na medida em que propõe uma licenciatura que integre no educador: o pensar, o ser e o fazer da educação" (B-1). 
Assim, construir um currículo equilibrado, na perspectiva da integração curricular, supõe fazer escolhas curriculares e organizar experiências formativas que mobilizem diversos tipos de conhecimentos, a fim de que o profissional em formação compreenda melhor a si mesmo e a realidade na qual está inserido.

\section{A centralidade da Prática Pedagógica}

Na perspectiva do currículo integrado, a iniciação à prática profissional se constitui como componente central no processo de formação inicial de professores. Esta, se bem articulada com os outros elementos do currículo, é capaz de se estabelecer como ponte epistemológica entre o conhecimento acadêmico e o conhecimento experiencial, advindo do exercício profissional.

Nos projetos pedagógicos, identificamos a Prática Pedagógica em dois sentidos: o primeiro, em que ela se apresenta como componente integrado às disciplinas do curso e, o segundo, em que a prática é considerada como eixo estruturante do curso, segundo mostram os seguintes fragmentos:

A relação teoria-prática estará integrada ao longo do curso, enfatizando-se no cotidiano escolar as dimensões ação-reflexão-ação. Adotando-se este princípio, a prática como componente curricular estará presente em todas as disciplinas curriculares (B-4).

Um dos princípios norteadores do Projeto Pedagógico é o da prática profissional como eixo norteador do projeto pedagógico. Esse princípio confere autoridade à implementação do programa, valorizando e colocando em destaque a discussão sobre a prática como eixo estruturante para o processo de ensino-aprendizagem (D-4).

No primeiro caso, percebemos que a proposta é de que a prática esteja presente em todas as disciplinas. No entanto, mesmo que a 
orientação seja por uma integração entre teoria e prática a partir do cotidiano escolar, corre-se o risco desta prática se apresentar de forma fragmentada, uma vez que a mesma pode estar a serviço da disciplina e, consequentemente, da especialização que ela traz em si, e não ao serviço da compreensão da docência e da formação do professor generalista.

Assumida como eixo estruturante do curso, como é o segundo caso, a Prática Pedagógica se apresenta como eixo norteador do processo formativo, deixando de ser vista como um domínio da aplicação da teoria, concentrada, geralmente, nos momentos finais do curso e denominada como estágio.

Para Formosinho e Niza (2009, p. 1222), "esta concepção tem conduzido a uma recentração da formação profissional sobre as práticas pedagógicas e, consequentemente, sobre a escola enquanto lugar de trabalho dos que praticam o ensino", fazendo com que os currículos de formação inicial de professores considerem a lógica da formação profissional.

Sendo a prática profissional o eixo estruturante do currículo, o movimento proposto para todos os componentes curriculares é que estes têm de buscar no exercício profissional da docência os conteúdos conceituais, factuais e procedimentais que devem constituir um corpus de aprendizagem, capaz de proporcionar aos formandos a integração "na" ação educativa, a fim de que eles transformem os saberes disciplinares em saberes profissionais.

\section{A organização curricular na perspectiva integrada}

Quanto às propostas de organização curricular, os projetos pedagógicos analisados indicam formas de integração consideradas inovadoras. Embora a estrutura disciplinar se encontre na base dos currículos, percebemos que as propostas curriculares integradas se desenvolvem tendo por base as disciplinas que tendem a ser sempre recontextualizadas (LOPES, 2008). 
Desta forma, identificamos a organização por eixos/núcleos temáticos e a existência de componentes integradores, como propostas sistematizadoras da integração curricular.

No que diz respeito à organização por eixos/núcleos temáticos, identificamos que muitos dos projetos organizam o currículo de modo que alguns temas centrais sejam considerados norteadores do percurso formativo, como evidencia o seguinte excerto:

Essa organização curricular estrutura-se em cinco eixos temáticos, assim delineados: I - Educação e Leitura de Mundo; II - Práxis Educativa e Produção do Conhecimento; III - Gestão de Sistemas e Espaços Educativos; IV - Trabalho Pedagógico e Aprendizagens; V - Atividades Formativas Integradoras (B-1).

Quanto à existência de componentes integradores, identificamos projetos pedagógicos em que a integração curricular fica sob a responsabilidade de uma única disciplina, como vemos a seguir:

O profissional em formação deverá experienciar, ao longo de sua formação, vivências que integrem as disciplinas de cada semestre. Este processo implica na dinamização do semestre através das disciplinas articuladoras - "PED". A "PED" deverá ser ofertada ao longo do curso e deverá ser o ponto de contato integrador entre as disciplinas que compõem o semestre (E-3).

Esta realidade mostra-nos como a matriz disciplinar clássica ainda é hegemônica no processo de organização curricular, procurando, entretanto, alguns espaços de integração, como é o caso da criação de disciplinas que atuem como articuladoras das outras disciplinas, comumente consideradas como isoladas.

No entanto, para que estas disciplinas atuem como integradoras, é necessário que o professor formador atue, primeiramente, como generalista e depois como especialista de um determinado conteúdo (BEANE, 2002, p. 53). Ou seja, é necessário que o professor tenha a capacidade de articular diferentes conhecimentos e diversas experiências em prol da formação profissional do formando. 


\section{Enraizamento do currículo nos contextos de trabalho}

Segundo Alonso (2002), a relação entre o currículo e o contexto é um dos pilares da organização curricular numa perspectiva integrada. Para a autora, é no contexto que o currículo encontra elementos a serem aprofundados no processo de aprendizagem, de modo que esta seja, cada vez mais, relevante.

No caso específico da formação de professores, esta articulação, sobretudo entre a formação e o contexto das escolas, é uma questão sine qua non para o desenvolvimento de um processo formativo profissional. Ou seja, quanto mais o contexto educacional estiver presente na formação de professores, mais esta formação terá melhores condições de responder às exigências complexas desse contexto.

Nos projetos analisados, verificamos a relação com o contexto educacional em um movimento de mão dupla: alguns projetos explicitam a necessidade de trazer o contexto para o interior da organização curricular, outros realçam a importância de inserir-se nele para com ele e nele construir o conhecimento profissional.

O primeiro movimento pode ser exemplificado pelo seguinte excerto:

Na formulação da matriz curricular do Curso de Pedagogia, a abordagem amazônica dessas temáticas corresponde tanto ao aprofundamento dos problemas e singularidades regionais quanto à necessidade de formação de processos identitários dos sujeitos estudantes da Amazônia (C-2).

Este movimento aponta, por um lado, a importância do contexto estar na base da configuração curricular, sobretudo quando este contexto cultural e social, para o qual e no qual os professores são formados, apresenta características tão peculiares. O que exige um rigoroso redimensionamento da linguagem, dos conteúdos, das estratégias metodológicas, entre outros, trabalhados no processo formativo. 
Por outro lado, apresenta a necessária construção da identidade profissional. Este processo identitário deve ser elaborado pelos formandos, a fim de que seu fazer profissional esteja em consonância com a realidade do contexto na qual seu exercício profissional irá se desenvolver.

O segundo movimento, diz respeito à inserção dos formandos nos contextos educacionais, diversos e plurais, para vivenciarem situações reais da realidade escolar. Vários projetos apresentam tal inserção da seguinte forma:

Propor a vivência de situações reais, inserindo o estudante no mundo do trabalho de modo a fomentar a formação de vínculo e co-responsabilidade com a realidade (B-4).

Também é indispensável que as situações de aprendizagem proporcionem um contato reflexivo efetivo com a realidade vivencial na qual o indivíduo está inserido e para a qual é formado (B-3).

Este trânsito entre formação e trabalho no contexto da formação inicial, definido por Canário (2001) como um movimento de alternância, valoriza a experiência e afirma que os professores também aprendem na escola a sua profissão, rompendo com o modelo tradicional, em que a teoria antecede a prática.

\section{A práxis enquanto ferramenta metodológica no modelo integrado de formação}

No modelo integrado de formação que nos serve de referencial para o estudo, a práxis é assumida enquanto ferramenta metodológica que deve perpassar todo o processo da construção curricular, desde os seus referenciais até ao seu desenvolvimento e consolidação, de modo que o mesmo seja coerente.

A práxis, enquanto movimento dialético de investigação-ação-reflexão, é desejável, tanto no processo de formação inicial de professores, 
quanto no seu exercício profissional, de forma que ele se aproprie, crie e recrie sua ação pedagógica, atribuindo um significado à relação entre a teoria e prática, de modo que não seja suficiente "a análise crítica da realidade, mas antes que esta deve conduzir à procura de práticas tranformadoras do estado das coisas existentes, à luz dos valores assumidos como desejáveis" (ALONSO, 1998, p. 110).

Os projetos analisados indicam a práxis, enquanto ferramenta metodológica fundamental, tanto para as atividades internas, realizadas na instituição de ensino superior que envolvem, sobretudo, as ações dos formadores, ainda que de forma isolada, mas que devem estar voltadas para a formação de futuros profissionais, capazes de atuar autonomamente, de modo que sua ação seja centrada em compromissos sociais; quanto para as atividades externas, relacionadas à prática e/ou estágio que devem ser desenvolvidas pelos formandos e que os deve favorecer no desenvolvimento de suas capacidades reflexivas, analíticas e críticas para uma tomada de decisão que transforme a ação e a realidade na qual estão inseridos

A noção de práxis situada como categoria central do trabalho pedagógico ou docente demonstra de um lado, para a 'epistemologia da prática', concebida como relação dialética entre teoria e prática, na qual conhecimentos (compreensão) e saber-fazer se articulam de modo crítico no encaminhamento de uma ação transformadora, resultando a produção do saber situado. Por outro lado, a noção de práxis se refere a uma intervenção crítica em situação na qual as relações intersubjetivas ocorrem na 'ecologia' do espaço e do tempo vivenciados pelos sujeitos em ação (B-1).

Estas duas questões provenientes da práxis, a epistemologia da prática, enquanto "estudo do conjunto dos saberes utilizados realmente pelos profissionais em seu espaço de trabalho cotidiano para desempenhar todas as suas tarefas" (TARDIF, 2002, p. 255), e a intervenção crítica no contexto, enquanto capacidade de compreendê-lo e desenvolver ações que o transformem, possibilitam novos sentidos para o trabalho 
pedagógico, de modo que este não se configure como uma prática mecânica e repetitiva, isenta da reflexão, mas que se mostra aberta, intencional e direcionada à transformação da realidade social a qual se circunscreve.

Este modo de configurar a relação entre a teoria e a prática qualifica a ação pedagógica como "uma atividade teórico-prática, que apresenta uma face ideal (teórica) e uma face material (prática) ajustada a objetivos que intencionam a transformação da realidade" (FELÍCIO, 2008, p. 40). Em outras palavras, a unidade entre a teoria e prática é condição sine qua non para assumirmos a práxis como uma dimensão e processo de integração no currículo de formação de professores, a fim de que o seu significado não se resuma a uma atividade teórica que não se materializa ou a uma atividade prática sem a produção de finalidades e conhecimentos que caracterizam a atividade teórica.

Noronha (2010) explicita que é, exatamente, esta relação que delimita o conceito de práxis no campo da formação de professores, uma vez que não existe práxis como atividade estritamente material, pois ela pressupõe a elaboração de finalidades e a produção de conhecimentos que caracterizam a atividade teórica, não sendo possível separar ou distinguir o que é prática, e o que é teoria.

Desta forma, a partir do entendimento de que esta "teoria prática" vai se constituindo, gradativamente, neste movimento dialético, os projetos pedagógicos analisados explicitam posturas e ações a serem construídas pelos formandos ao longo do processo formativo, como podemos verificar a seguir:

A ação educativa, traçada a partir da relação entre a teoria e a prática, assume uma projeção da formação orientada na e para a práxis. Isso significa que o docente, ao longo do processo formativo, vai adquirindo conhecimentos sobre o seu trabalho e transformando-os em ação. Isso implica naturalmente que o docente em formação desenvolva as seguintes aptidões:

- Domínio de conhecimentos específicos em torno dos quais deverá agir;

- Compreensão de questões envolvidas em seu trabalho, sua identificação e resolução; 
- Autonomia e segurança para tomar decisões;

- Responsabilidade ao fazer opções;

- Atuação crítica no contexto em que atua;

- Abertura para interagir cooperativamente com a comunidade profissional a que pertence e com a sociedade (B-3).

Conceber a formação de professores em uma perspectiva integrada do currículo, supõe reconhecer que essas aptidões são desenvolvidas nas possibilidades que o próprio processo oferece aos formandos de desenvolvê-las, não como "saber", somente, mas como "saber e saber fazer", necessitando, assim de experiências concretas e significativas.

Entretanto, não basta atribuir, unicamente, aos formandos a responsabilidade de desenvolver tais aptidões, valores e ações ao longo do processo formativo. Faz-se necessário que, no interior dos cursos de formação, os professores formadores, em seu cotidiano, assumam esta premissa como eixo norteador que se desdobra em estratégias reflexivas, coletivas e colaborativas do próprio percurso formativo em que estão inseridos e de seu desenvolvimento profissional enquanto professor do ensino superior.

É neste sentido que Alonso (1998) propõe a investigação-ação, reflexiva e colaborativa, como uma estratégia formativa para que os professores, em seus contextos, sejam capazes de desenvolver uma práxis profissional que contribua para a melhoria do ensino.

Nos projetos pedagógicos analisados, verificamos que a investigação-ação é uma metodologia proposta para a realização da prática pedagógica e/ou estágio. Ou seja, é uma estratégia a ser utilizada pelos formandos em suas experiências formativas no contexto profissional. No entanto, esta investigação-ação, que intenciona melhorar o ensino, deve ser uma estratégia utilizada também no Ensino Superior, pelos professores envolvidos no processo de formação destes futuros professores, tendo as suas práticas formativas como objeto de análise, reflexão, crítica e superação, a partir de uma perspectiva coletiva e colaborativa. Só assim faz sentido pensar em um modelo integrado de formação inicial de professores. 


\section{Considerações finais}

A análise dos Projetos Pedagógicos dos cursos de Pedagogia das Universidades Federais Brasileiras, à luz do Modelo Integrado de Formação, nos indicou que, embora esta formação seja caracterizada pela hegemonia disciplinar e pela relação linear entre teoria e prática, explicitam elementos daquele modelo que intencionam favorecer experiências integradoras no currículo de formação inicial de professores.

Ao identificarmos a intencionalidade por um trabalho curricular mais flexível, equilibrado e aberto à compreensão da realidade educacional, nos deparamos com propostas formativas que foram capazes de alargar sua concepção de currículo, valorizar o contexto e propor experiências formativas que mobilizem diversos tipos de conhecimentos.

Da mesma forma, as propostas de integrar o conhecimento por eixos/núcleos temáticos ou pela existência de um componente curricular integrador, nos mostram um avanço no que diz respeito à organização curricular e às formas de integração do conhecimento.

Tal avanço se inscreve no reconhecimento de que a valorização das fronteiras disciplinares contribuem para que o conhecimento fique centrado nele próprio, impedindo que o mesmo seja utilizado como ferramenta para a compreensão da realidade educativa, a qual exige deste profissional a mobilização de saberes, atitudes e competências relevantes e com potencial transformador da prática profissional.

Percebemos, também, o redimensionamento da prática pedagógica que deixa de ser vista como um componente para a aplicação de teorias, para ser assumida como eixo estruturante que dá significado ao curso. Ou seja, o reconhecimento da prática profissional, enquanto lugar de encontro entre teoria e prática, "da qual" e "para qual" converge o transcurso formativo, alimentado por uma atitude investigativa e reflexiva capaz de desenvolver um processo contínuo de investigação-ação-reflexão, que permita reformulações de teorias e práticas em favor do processo educativo. 
No entanto, experiências pontuais não são suficientes para abarcar a complexidade da formação e do contexto de atuação profissional. É necessário reconhecer o caráter transformador da integração curricular, como possibilidade de superação da visão dual que tem acompanhado a formação de professores, considerando ser "fundamental a exigência de um projeto de formação e a construção de um perfil profissional que permita o desenvolvimento de um currículo formativo integrado" (SILVA, 2011, p. 588).

\section{Referências}

ALONSO, L. Inovação Curricular, Formação de Professores e Melhoria da escola Uma abordagem reflexiva e reconstrutiva sobre a prática da inovação/formação (Vol. I e II). Tese (Doutoramento em Estudos da Criança ) - Universidade do Minho/Instituto de Estudos da Criança, Braga, 1998.

ALONSO, L. Para uma teoria compreensiva sobre integração curricular - O contributo do Projecto "PROCUR". Investigação e Práticas, 2002.

ALONSO, L. Perfil profissional e projecto de formação. In: LOPES, A. (org.). De uma escola a outra: Temas para pensar a formação inicial de professores. Porto: Edições Afrontamento / CIIE., 2007.

ALONSO, L.; SILVA, C. Questões críticas acerca da construção de um currículo formativo integrado. In: ALONSO, L.; ROLDÃO, M. C. (coords). Ser Professor do 1. Ciclo: Construindo a Profissão. Coimbra: Livraria Almedina / Centro de Estudos da Criança, 2005.

BEANE, J. A. Integração Curricular: A concepção do núcleo da educação democrática. Lisboa: Didáctica Editora, 2002.

BRASIL. Diretrizes Curriculares Nacionais para a Educação Básica. CNE/CEB. Brasília: Diário Oficial da União, 14/07/2010. 
CANÁRIO, R. A prática profissional na formação de professores. In: CAMPOS, B. P. (org.). Formação Profissional de Professores no Ensino Superior. Porto: Porto Editora/INAFOP. 2001.

FELÍCIO, H. M. S. Currículo e Emancipação: Redimensionamento de uma escola instituída em um contexto advindo do processo de desfavelização. Tese (Doutorado em Educação) - Pontifícia Universidade Católica de São Paulo, São Paulo, 2008.

FORMOSINHO, J. A academização da formação de professores. In: FORMOSINHO, J. (coord). Formação de Professores: Aprendizagem profissional e aação docente. Porto: Porto Editora, 2009.

FORMOSINHO, J.; NIZA, S. Iniciação à prática profissional nos cursos de formação inicial de professores. In: FORMOSINHO, J. (coord.). Formação de Professores: Aprendizagem profissional e acção docente. Porto: Porto Editora, 2009.

LOPES, A. C. Políticas de Integração Curricular. Rio de Janeiro: EdUERJ, 2008.

MUÑOZ, J. M. La formación del profesorado y la garantía del derecho a una buena educación para todos. In: ESCUDEIRO, J. M.; GÓMEZ, (editores), La Formación del Profesorado y la Mejora de la Educación. Barcelona: Ediciones Octaedro. 2006.

NORONHA, O. M. Epistemologia, Formação de Professores e Práxis Educativa Transformadora. Quaestio, Sorocaba, SP, v. 12, p. 5-25, 2010.

SILVA, C. M. Tornar-se Professor: Desenvolvimento Curricular e Construção do Conhecimento Profissional (Vol. I e II). Tese (Doutoramento em Estudos da Criança ) - Universidade do Minho/Instituto de Educação, Braga, 2011.

TARDIF, M. Saberes Docentes e Formação Profissional. Petrópolis: Vozes, 2002.

Recebido: 30/11/2015

Received: $11 / 30 / 2016$

Aprovado: 04/09/2016

Approved: 09/04/2016 